[Jpn. J. Agric. Econ. Vol.21, pp.63-67, 2019]

\title{
Seasonality of Staple Food Prices in Ethiopia: Does Warehouse Service Matter?
}

\author{
Solomon Bizuayehu Wassie ${ }^{1,2}$, Hitoshi Kusakari $^{1^{*}}$ and Masahiro Sumimoto ${ }^{3}$
}

Using 128 domestic and international monthly price series of four commodities, this study demonstrates how and to what extent warehouse service affects seasonality of food prices in Ethiopia. The study also examines the characteristics and degree of food price seasonality in the country. Our result shows that there is significant variation in the seasonal gap amongst crops - i.e. the highest seasonal gap being for maize $(20 \%)$. We also find that $10-14 \%$ of monthly price volatility in Ethiopia is explained by its seasonality. Most importantly, our result reveals that availability of warehouse service has lessen the food price seasonal gap in Ethiopia.

Key words: Ethiopia, price seasonality, warehouse service

\section{Introduction}

Seasonality refers to the intra-annual variability of the monthly price that is specifically related to the crop cycle (Manda, 2010; Gilbert et al., 2017). In fact, given associated storage and opportunity costs, the difference between prices before and after harvest of storable crops is unavoidable (Kaminski et al., 2014). Therefore, even when markets are efficient, a certain degree of food price seasonality is inevitable. However, seasonality will be more pronounced when access to storage and credit facilities are limited (Gilbert et al., 2017). Previous studies also prevailed that the extent of food price seasonality (hereafter seasonal gap) in developing countries is 2 to 3 times higher than the international reference market (Kaminski et al., 2016; Gilbert et al., 2017).

As a typical developing country located in Sub-Saharan Africa, studying seasonality of staple food price in Ethiopia is therefore important mainly for the following three reasons. First of all, there is a strong negative association between seasonality of food price and intra-annual consumption ${ }^{1)}$ in Ethiopia (Dercon and Krishnan, 2000; Hirvonen et al., 2016) and elsewhere (Kaminski et al., 2016). Specifically, consumption of the poor is highly price-responsive and hence suffers from food insecurity during the peak periods of food price (Manda 2010, Woldehanna and Tafere 2015).

Second of all, seasonality (predictable component) is one feature of food price volatility (Woldehanna and Tafere,

\footnotetext{
${ }^{1}$ Kobe University

${ }^{2}$ Bahirdar University, Ethiopia

${ }^{3}$ Ishikawa Prefectural University

Corresponding author*: frontier@kobe-u.ac.jp
}

2015; Gilbert et al., 2017) that discourages smallholder farmers from investing to improve their farm income (Byerlee et al. 2006, Jayne et al. 2006, Manda 2010, Baffes et al. 2017). Over the last decade, there has been high food price volatility in Ethiopia. The government has also acknowledged the problem and attempted to take regulatory measures to resolve the potential welfare loss (Woldehanna and Tafere, 2015). Yet the problem retains. Hence, understanding the characteristics and extent of food price seasonality will help to draw behavioral inferences and design appropriate policy intervention to stabilize the market.

The last, perhaps more important, reason is that there exists only little systematic evidence on the extent and characteristics of food price seasonality in Ethiopia. In general, food price seasonality has been an important subject in the 1990s, till it was neglected mainly due to the general perception of improved integration of local food markets (Kaminski et al., 2016). In fact, recently, the focus on price seasonality has revived (e.g. Baffes et al., 2017; Gilbert et al., 2017; Kaminski et al., 2014, 2016; Manda, 2010). Yet the issue is less studied in the case of Ethiopia. Moreover, with the exception of Gilbert et al. (2017), available studies are dated (Dercon and Krishnan, 2000).

In their comprehensive study on seasonality of food price in Africa, Gilbert et al. (2017) have considered Ethiopia as one of thier case study countries. However, the current study is unique in three aspects. First, using the most recent data

1) Seasonal price variability may translate into seasonal variation in (food) consumption when capital markets fail and off-farm employment or migration are inadequate to cope with (Kaminski et al., 2014). 
(i.e. 2010 to 2017), this study examines price seasonality of both retail and wholesale markets in Ethiopia. Second, the study analyzes seasonality of wheat and mixed teff which are amongst the top staple crops in Ethiopia. Most importantly, besides estimating the extent of food price seasonality, this study extends the analysis and examines the effect of warehouse services on food price seasonal gap in the country.

Briefly, in our context, warehouse service refers to a service provided by the Ethiopian Commodity Exchange (ECX), established in 2008. The ECX has 17 warehouses all over the country, including in 4 markets (Addis Ababa, Gondar, Adama, and Nekemit) considered in this study (Gabre-madhin, 2012). The benefit of using warehouse service is twofold. While storing their $\mathrm{crop}^{2)}$ in a reliable warehouse, farmers can also use the issued warehouse receipt as loan collateral to access finance without actually selling their produce (Gabre-Madhin and Goggin 2005). Here it is worth noting that ECX eases the process to get credit by providing legal receipt which can be used as collateral, but it does not provide credit directly. Yet, presumably, this could lessen the price seasonal gap by encouraging storage immediately after harvest - i.e. when the price is low.

Therefore, this study is motivated to demonstrate how and to what extent warehouse service affects seasonality of food prices in Ethiopia. Furthermore, the study also examines the characteristics and degree of staple food price seasonality in the country. In a nutshell, our result shows that warehouse service has statistically significant effect on food price seasonal gap in Ethiopia. The rest of the paper is organized as follows: The next section describes the data and estimation strategy. Section 3 presents the main result of the study and the last section concludes with policy implications.

\section{Data and Estimation Strategy}

\section{1) Data source and description}

This study uses a monthly food price data (from July 2010 to April 2017) collected by the Ethiopian Grain Trade Enterprise (EGTE) and International Monetary Fund (IMF) ${ }^{3)}$. Specifically, we consider teff), wheat and maize which are dominantly produced (i.e. all together account for $60 \%$ of total grain production) and consumed in Ethiopia (CSA, 2017). Therefore, the result of this study is based on 126 price series (65 wholesale and 61 retail markets) of four

2) Coffee, sesame, haricot beans, maize and wheat are commodities transacted through ECX, details available on http://www.ecx.com.et/commodities.aspx. commodities - namely, white teff, mixed teff, white wheat, and maize - in Ethiopia. Moreover, to compare the domestic price seasonality with the global market, we consider the international prices of wheat and maize at USA market - i.e. major exporter of wheat and maize contributing $13 \%$ and $38 \%$ of the global export, respectively (USDA, 2018). Thus, estimation is done using monthly price series of each crop by markets which contain 82 observations.

\section{2) Estimation strategy}

A common approach to characterize seasonality is to estimate unrestricted 12-month seasonal factors. A key attractive feature of the unrestricted dummy variable regression is that no prior structure is imposed on the form of seasonality. However, long years of time-series data is required to obtain accurate estimates of seasonal factors (Kaminski et al., 2016). This is especially problematic (i.e. sensitive to outliers) when the seasonal gap is measured as the difference between the maximum and minimum seasonal factor. This weakness of the dummy variable approach can be mitigated by using a trigonometric function which is more parsimonious. By imposing a harvest-based pattern on the trend of monthly seasonality factors, the trigonometric function approach reduces the influence of any single monthly price data (Gilbert et al., 2017).

Generally, when data samples are short or seasonal processes are poorly defined, the trigonometric seasonality approach provides less (upward) bias and hence are preferred to the dummy variable approach (Kaminski et al., 2016; Gilbert et al., 2017). Accordingly, following previous studies (Kaminski et al., 2014; Gilbert et al., 2017), the twoparameter trigonometric seasonality approach is employed in this study. With a trending data, the seasonal parameters to be used to calculate seasonality of each commodity can be estimated as:

$$
\Delta P_{y m}=\gamma+\alpha \Delta \cos \left(\frac{m \pi}{6}\right)+\beta \Delta \sin \left(\frac{m \pi}{6}\right)+v_{y m}
$$

where $\Delta P$ is change in log price of the commodity, $y$ indexes year, $m$ indexes month, $\pi$ is a number approximately equal to $3.142, \alpha$ and $\beta$ are parameters to be estimated, and $v_{y m}$ is error term. The stationarity test (available up on request) confirms that $\Delta P$ is stationary. Hence, for each market monthly price series, equation $(1)^{5)}$ is estimated by ordinary least squares. And the standard

3) We thank EGTE and IMF for providing the data.

4) Teff is small grain cereal originally from Ethiopia.

5) Seasonal effects are generally higher at times of higher prices than 
regression $R^{2}$ value measures the share of price volatility explained by its seasonal component.

Once seasonal parameters are estimated, seasonality can be calculated following Equation (2) below:

$$
S_{m}=\alpha \cos \left(\frac{m \pi}{6}\right)+\beta \sin \left(\frac{m \pi}{6}\right)=\lambda \cos \left(\frac{m \pi}{6}-\omega\right)
$$

where $S_{m}$ refers to seasonality, $\lambda=\sqrt{\alpha^{2}+\beta^{2}}$ and $\omega=\tan ^{-1}\left(\frac{\alpha}{\beta}\right)$. The parameter $\lambda$ measures the seasonal amplitude and implies a seasonal gap of $2 \lambda$. The seasonal gap measures the percentage change in price between preharvest and post-harvest seasons in which the price is at its peak and trough, respectively.

\section{Result and Discussion}

Using a total of 126 price series of four commodities, this study estimates the extent and characteristics of staple food price seasonality in Ethiopia. For example, the reported value of white teff at the wholesale market (8.2) is the average of estimated seasonal gaps at $\mathrm{N}=17$ wholesale markets. Overall, the unconditional mean comparison test result shows insignificant difference in price seasonality of wholesale and retail markets, for all considered commodities (Table 1).

Table 1. Seasonal gap of crops by market type

\begin{tabular}{llllll}
\hline \multirow{2}{*}{ Commodity } & \multicolumn{4}{c}{ Market type } & \\
\cline { 2 - 5 } & $\mathrm{N}$ & Wholesale & $\mathrm{N}$ & Retail & p-value \\
\hline White Teff & 17 & $8.2(3.6)$ & 16 & $8.1(3.5)$ & 0.96 \\
Mixed Teff & 17 & $9.2(3.9)$ & 16 & $9.5(4.5)$ & 0.80 \\
White wheat & 15 & $13.6(2.9)$ & 14 & $12.6(2.6)$ & 0.35 \\
Maize & 16 & $20.3(5.6)$ & 15 & $19.9(6.0)$ & 0.86 \\
Total & 65 & $12.7(6.3)$ & 61 & $12.4(6.3)$ & 0.82 \\
\hline
\end{tabular}

Notes: 1) Estimated parameters at each market location are based on a monthly time series data from July 2010 to April 2017 - i.e. 82 observations. 2) Reported statistics are average seasonal gaps with their standard errors in brackets. 3) p-values refers to null hypothesis of no mean difference between wholesale and retail markets.

The price seasonal gap for maize is nearly $20 \%$ both at wholesale and retail markets, which is much higher compared to USA international maize market (6.03\%) during the same period. Indeed, previous studies in Malawi also found even higher (nearly 60\%) maize price seasonal gap (Manda, 2010; Gilbert et al., 2017). Likewise, wheat price

when prices are low, hence, it is more appropriate to use logarithms of prices (Kaminski et al., 2014). Furthermore, even if price series seasonal gap at wholesale and retail markets is more than threefold of the seasonal gap at USA international wheat market $(3.39 \%)$. This result suggests that there is "excess" seasonal gap in Ethiopia which needs due attention. On the other hand, seasonality of white teff and mixed teff are nearly $8 \%$ and $9 \%$, respectively, in both markets.

The world market price can play an important role in determining the domestic price and hence price seasonal gap of imported crops. Amongst the commodities considered in this study, wheat is an increasingly imported cereal in Ethiopia. From 2010 to 2015, the total value of wheat import in the country has increased by $21 \%$. However, this growth is expected to be moderated by the anticipated increase in local wheat production and the private sectors' difficulty in accessing enough foreign exchange - i.e. foreign exchange reserve of Ethiopia was estimated to be less than 2 months of import coverage (Francom, 2017). Hence, to this end, the "excess" price seasonal gap in Ethiopia could be due to either or both of the following reasons: (i) due to poor infrastructure and storage services, which in turn could lead to less integration of domestic markets; or (ii) because of poor integration of the domestic markets with the world market, following difficulty to get foreign exchange by the private importers (Ansah et al., 2014).

Extending further, we run (Bonferroni) multiple comparison test and evaluate the difference in seasonality amongst commodities. Accordingly, as shown in Table 2, our result confirms that seasonality is significantly higher for maize followed by wheat - i.e. on average, seasonality of maize is $12 \%, 11 \%$, and $7 \%$ higher than white teff, mixed teff, and wheat respectively. Similarly, the seasonal gap for wheat is significantly higher than that of white teff and mixed teff. The variation in seasonality amongst crops is consistent with previous studies (Kaminski et al., 2014).

Table 2. Seasonal gap comparison of crops

\begin{tabular}{llll}
\hline Crop type & White teff & Mixed teff & White wheat \\
\hline Mixed teff & 1.16 & & \\
& $(1.13)$ & & \\
White wheat & $4.98 * * *$ & $3.82 * * *$ & \\
& $(4.67)$ & $(3.58)$ & \\
Maize & $11.96 * * *$ & $10.8 * * *$ & $6.9 * * *$ \\
& $(11.41)$ & $(10.30)$ & $(6.45)$ \\
\hline
\end{tabular}

Notes: 1) The reported values are row mean - column mean and values in bracket are t-statistics. 2) *** is $1 \%$ significance level.

are not trend stationary, they will generally be difference stationary (Kaminski et al. 2016). 
Seasonality (known fluctuation) contributes to (domestic) price volatility (Gilbert et al., 2017). Accordingly, Table 3 presents the share of price volatility explained by its seasonal component. The result shows that $10 \%$ of white teff price volatility in both wholesale and retail markets is attributed to its seasonality. Similarly, seasonality explains $10 \%, 12 \%$ and $14 \%$ of price volatility in mixed teff, wheat, and maize wholesale markets, respectively. In fact, a study in Tanzania and Uganda also showed that seasonality explains $20 \%$ of the monthly price volatility (Kaminski et al., 2014).

Table 3. Share of seasonality in price volatility

\begin{tabular}{lccccc}
\hline \multirow{2}{*}{ Crop type } & \multicolumn{2}{c}{ Wholesale market } & & \multicolumn{2}{c}{ Retail market } \\
\cline { 2 - 3 } \cline { 5 - 6 } & $\mathrm{N}$ & Seasonal R $^{2}$ & & $\mathrm{~N}$ & Seasonal R \\
\hline White teff & 17 & 0.10 & & 16 & 0.10 \\
Mixed teff & 17 & 0.10 & & 16 & 0.08 \\
White wheat & 15 & 0.12 & & 14 & 0.11 \\
Maize & 16 & 0.14 & & 15 & 0.14 \\
\hline
\end{tabular}

Note: $\mathrm{N}$ refers to the number of markets and reported values are average of all markets.

In general, price seasonality explains less than $15 \%$ of food price variability in Ethiopia. Yet it is higher compared to the international maize (3\%) and wheat (1\%) markets during the same period. This result implies that any attempt to reduce "excess" food price seasonality in Ethiopia will, somehow, help to resolve the acute price instability in the country. However, we acknowledge that nearly $85 \%$ or even more of the variation in price is due to factors other than seasonality. Hence, future studies should consider investigating other possible options to resolve price volatility.

Another important question posited in the introduction section is how and to what extent the warehouse service will affect seasonality of food price. To this end, we performed two exercises to examine the effect of warehouse service on the food price seasonal gap. First, we attempted to visually demonstrate the effect of warehouse service on price seasonal gap (Figure 1). The vertical axis of Figure 1 measures estimated seasonal gap (\%) and the horizontal axis represents the availability of warehouse service (yes $=$ if there is warehouse service) and commodity type. Moreover, while the box represents $25^{\text {th }}$ to $75^{\text {th }}$ percentile of the observations, the diamond within the box refers to the median.

6) Ordinary least squares estimation result, using same covariates, shows that availability of warehouse service significantly decreases price seasonal gap of wheat and maize by $8.4 \%(\mathrm{P}$
The figure clearly illustrates that the median seasonal gap for wheat and maize is smaller in the markets with access to warehouse service than otherwise. Here, it is important to note that there is no such clear difference in the case of white teff and red teff, which is consistent with our expectation as these commodities are not considered in the warehouse service. The unconditional mean difference also shows that seasonal gap for wheat and maize is $3.54 \%(\mathrm{p}=0.03)$ and $2.17 \%(p=0.38)$ lower in favor of markets with access to warehouse service, respectively.

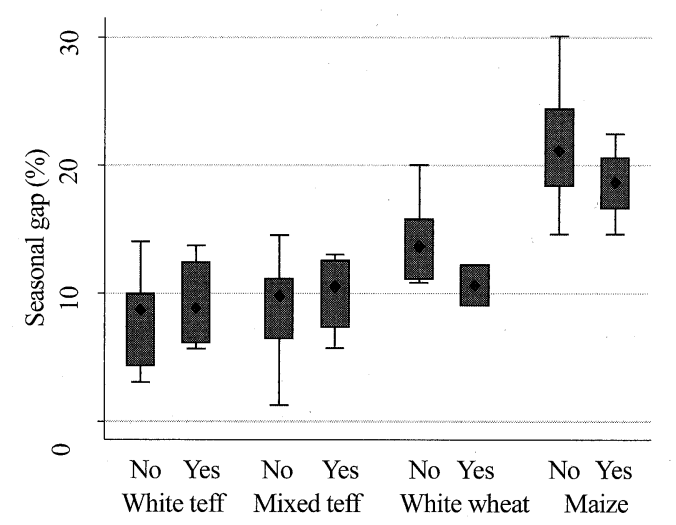

Figure 1. Seasonality gap of crops by availability of warehouse service (wholesale market)

In fact, we cannot draw a conclusion based on the results of either the unconditional mean difference or Figure 1 mainly because it could be partially or totally due to other confounding factors. Hence, in the second exercise, while accounting for potential variations by commodity, market type, and location-specific heterogeneity, we examine the effect of warehouse service on seasonality by using the conventional analysis of variance (ANOVA) method. Intuitively, ANOVA helps to assess the potential differences in a continuous dependent variable by variables having two or more categories. The dependent variable in this analysis is estimated seasonal gap of 60 price series of wheat and maize.

Table 4 presents ANOVA result for wheat and maize markets. The result shows that access to warehouse service has a statistically significant effect on price seasonal gap ${ }^{6}$ i.e. explaining nearly $5 \%$ of the variation in the extent of price seasonality. The result also confirms that there is significant variation in seasonal gap amongst crops. Overall, $67 \%$ of the

value $=0.00$ ). Full estimation result is not reported for brevity, but it is available up on request. 
total variation in the wheat and maize price seasonal gap was explained by the variables in the model. Furthermore, we replicate the analysis by using 126 estimated seasonal gaps of all crops, as a consistency check, and get similar results. These results suggest that, improving access to warehouse services is an important area of interventions to resolve the "excess" seasonal gap in the country.

Table 4. Analysis of variance on seasonal gap

\begin{tabular}{lll}
\hline Description & $\%$ explained & F-statistics \\
\hline Warehouse service (yes/no) & 4.80 & $5.94 * * *$ \\
Crop (wheat/ maize) & 35.4 & $43.53 * * *$ \\
Market (wholesale /retail) & 0.40 & 0.55 \\
Market location & 26.0 & $2.01 * *$ \\
Observation & 60 & \\
R-squared & 0.67 & \\
\hline
\end{tabular}

Notes: 1$)^{* * *}$ and $* *$ refers to $1 \%$ and $5 \%$ significance level respectively. 2) \% explained refers to the proportion of variance explained by each factor. 3) market location is location dummy.

\section{Conclusions}

Using monthly price data from 17 domestic and 2 international markets, this study examines the characteristics and extent of staple food crops' seasonality in Ethiopia. Above all, the study demonstrates the effect of warehouse service on food price seasonal gap in the country. Our result shows that while there is no detectable seasonal gap difference between wholesale and retail markets, there is a considerable difference by commodity -i.e. the highest being for maize $(20 \%)$. We also find that the extent of seasonality in Ethiopia is "excess" compared to the international market. Furthermore, the result prevailed that price seasonality explains $10-14 \%$ of monthly food price volatility. Last, perhaps more importantly, the result shows that availability of warehouse service has a statistically significant association with price seasonal gap - explaining nearly $5 \%$ of the variation in the price seasonal gap of wheat and maize.

Altogether, these findings suggest that improving access to warehouse services will have a considerable contribution in resolving the acute seasonality of food price in Ethiopia. Furthermore, amongst considered commodities, maize is a priority crop that needs due attention towards minimizing the "excess" seasonal gap. The scope of this study is limited to estimating the level of seasonality and evaluating the role of warehouse services in stabilizing the food market. Hence, future studies should go further and identify which characteristics of crops and markets are major determinants of price seasonal gap.

\section{References}

Ansah, I. G., C. Gardebroek, R. Ihle, and M. Jaleta (2014) Analyzing Developing Country Market Integration with Incomplete Price Data Using Cluster Analysis, International Agricultural Trade Research Consortium's (IATRC's). San Diego, CA.

Baffes, J., V. Kshirsagar, and D. Mitchell (2017) What Drives Local Food Prices? Evidence from the Tanzanian Maize Market, The World Bank Economic Review: 1-25.

Byerlee, D., T. S. Jayne, and R. J. Myers (2006) Managing Food Price Risks and Instability in a Liberalizing Market Environment: Overview and Policy Options, Food Policy 31(4): 275-287.

Dercon, S. and P. Krishnan (2000) Vulnerability, Seasonality and Poverty in Ethiopia, Journal of Development Studies 36(6): 2553.

Francom, M. G. (2017) Ethiopia's Ag. Imports Continue Growing, GAIN Report Number ET1634, Addis Ababa.

Gabre-madhin, E. (2012) A Market for Abdu: Creating a Commodity Exchange in Ethiopia, International Food Policy Research Institute (IFPRI).

Gabre-Madhin, E. Z. and I. Goggin (2005) Does Ethiopia Need a Commodity Exchange? An Integrated Approach to Market Development, EDRI-ESSP Working Paper No. 4, Addis Ababa.

Gilbert, L., L. Christiaensen, and J. Kaminski (2017) Food Price Seasonality in Africa: Measurement and Extent, Food Policy 67: 119-132.

Hirvonen, K., A. S. Taffesse, and I. W. Hassen (2016) Seasonality and Household Diets in Ethiopia, Public Health Nutrition 19(10): 1723-1730.

Jayne, T. S., B. Zulu, and J. Nijhoff (2006) Stabilizing Food Markets in Eastern and Southern Africa, Food Policy 31(4): 328-341.

Kaminski, J., L. Christiaensen, and C. L. Gilbert (2014) The End of Seasonality? New Insights from Sub-Saharan Africa, World BankPolicy Research Working Paper 6907, The World Bank Africa Office.

Kaminski, J., L. Christiaensen, and C. L. Gilbert (2016) Seasonality in Local Food Markets and Consumption: Evidence from Tanzania, Oxford Economic Papers 68(3): 736-757.

Manda, E. L. (2010) Price Instability in the Maize Market in Malawi, Doctoral Thesis submitted to University of East Anglia.

USDA (2018) Grain: World Markets and Trade, United States Department of Agriculture.

Woldehanna, T. and Y. Tafere (2015) Food Price Volatility in Ethiopia: Public Pressure and State Response, IDS Bulletin 46(6): 76-83. 